\title{
ECONOMÍA CIRCULAR: LÍNEAS MAESTRAS DE UN CONCEPTO JURÍDICO EN CONSTRUCCIÓN
}

\section{CIRCULAR ECONOMY: MAIN ASPECTS OF A LEGAL CONCEPT UNDER CONSTRUCTION}

\author{
RENÉ JAVIER SANTAMARÍA ARINAS \\ Profesor Titular de Derecho Administrativo \\ Universidad de La Rioja' \\ rene-javier.santamaria@unirioja.es
}

Fecha de recepción: 17 de abril de 2019 / Fecha de aceptación: 31 de mayo de 2019

RESUMEN: Tras repasar los principales hitos que jalonan la recepción del concepto en documentos políticos de la Unión Europea, este trabajo analiza las primeras definiciones de economía circular que han aparecido en normas internas con rango de ley tratando de encontrar en ellas el porqué y el para qué del esfuerzo que en estos momentos se está llevando a cabo para su juridificación. Comprobado que tales causas y fines plantean cierto grado de exigencias novedosas respecto de las que el Derecho juega un papel instrumental, a continuación se examina también el cómo hacerlas efectivas; es

\footnotetext{
1 Este trabajo se ha elaborado en el marco del proyecto internacional de investigación que lleva a cabo la Red Temática "Justicia y Sostenibilidad en el Territorio a través de Sistemas de Infraestructuras de Datos Espaciales" (JUST-SIDE), coordinada desde la Universidad de Coimbra y financiada por el Programa lberoamericano de Ciencia y Tecnología para el Desarrollo (CYTED). Y, desde 2019, también en el del Proyecto "El Derecho Español ante los Retos Inminentes de la Economía Circular" (DERIEC); referencia RTI2018-097216-B-I00, financiado por el Programa Estatal de I+D+i Orientada a los Retos de la Sociedad de la Agencia Estatal de Investigación del Ministerio de Ciencia, Innovación y Universidades y cofinanciado por el Fondo Europeo de Desarrollo Regional (FEDER).
} 
decir, el alcance de las transformaciones jurídicas requeridas en esta etapa inicial, sin dejar de apuntar espacios para posibles avances en su previsible evolución posterior.

RESUM: Després de repassar les principals fites que delimiten la recepció del concepte en documents polítics de la Unió Europea, aquest treball analitza les primeres definicions d'economia circular que han aparegut en normes internes amb rang de llei i intenta trobar-hi les causes i finalitats de l'esforç que en aquests moments es du a terme per a la seva juridificació. Un cop comprovat que aquestes causes $\mathrm{i}$ finalitats plantegen un cert grau d'exigències noves respecte de les quals el dret juga un paper instrumental, s'examina com fer-les efectives, és a dir, l'abast de les transformacions jurídiques requerides en aquesta etapa inicial, sense deixar d'apuntar espais per a possibles avanços en la seva previsible evolució posterior.

ABSTRACT: This paper analyzes the initial definitions of circular economy stated in several spanish laws. Such analysis starts from the process of receiving the concept in political documents of the European Union. The objective is to understand the causes and purposes of the current effort towards the juridification of circular economy concept. These causes and purposes pose new demands, with respect to which Law plays an instrumental role. Finally, the paper focuses on how to make these demands effective at the legal level. That is to say, it is intended to determine the scope of the legal transformations required in this initial stage, and in subsequent stages of development.

PALABRAS CLAVE: Desarrollo sostenible - Economía circular - Capital natural Eficiencia en el uso de recursos - Cadenas de valor -- Flujos de materiales.

PARAULES CLAU: Desenvolupament sostenible - Economia circular - Capital natural Eficiència en l'ús de recursos - Cadenes de valor -- Fluxos de materials.

KEY WORDS: Sustainable development - Circular economy - Natural capital -Efficiency in the use of resources - Value chains - Material flows. 
SUMARIO: 1. INTRODUCCIÓN. 2. LA RECEPCIÓN DEL CONCEPTO EN EL ÁMBITO JURÍDICO. 2.1. Antecedentes. 2.2. Evolución en el ordenamiento jurídico interno. 3. PRINCIPALES RASGOS CARACTERÍSTICOS DE UN CONCEPTO JURÍDICO EN CONSTRUCCIÓN. 3.1. Etiología: causas de la juridificación del concepto. 3.2. Teleología: un objetivo político relativamente transformador. 3.3. Metodología: ¿un principio sectorial 0 general? 4. EL ALCANCE DE LAS PRIMERAS TRANSFORMACIONES JURÍDICAS REQUERIDAS. 4.1. Producción. 4.2. Consumo. 4.3. Gestión de residuos. 4.4. Mercado de materias primas secundarias. 5. CONCLUSIONES. Bibliografía.

\section{INTRODUCCIÓN}

Se han documentado más de cien definiciones del concepto de economía circular [KIRHHERR et alii (2017)] cuya interpretación sigue suscitando intensas discusiones en un debate que tiene carácter global y multidisciplinar ${ }^{2}$. Sin embargo, este trabajo constata que tal locución se ha incorporado rápidamente al discurso político dominante y empieza a proliferar también en textos jurídicos (2). Y, puesto que en ellos se confía al Derecho la tarea de ordenar la transición hacia un "cambio sistémico", nada menos, el término se convierte así en objeto de atención también para los juristas. Pero sabido es que un significante puede no tener el mismo significado en diferentes contextos. Resulta, por tanto, necesario esclarecer, hasta donde sea posible, el sentido y los principales rasgos característicos de un concepto jurídico todavía en construcción (3). Se observa así que, en abstracto, entraña un enorme potencial transformador de la economía y de la sociedad ante el que el Derecho asume un papel instrumental. Pero también que, al concretarse en objetivo político en determinadas circunstancias de tiempo y lugar, admite distintos grados de ambición, lo que acaba condicionando el alcance de las transformaciones jurídicas requeridas por el momento (4).

\section{LA RECEPCIÓN DEL CONCEPTO EN EL ÁMBITO JURÍDICO}

\subsection{Antecedentes}

En la Unión Europea la noción de "economía circular" se maneja al menos desde el año 2005 (SANTAMARÍA ARINAS, 2011). De hecho, se alude

2 Baste reparar al respecto en el pluralismo que reflejan, tanto por el origen y especialidad de sus autores como por sus respectivos enfoques y contenidos, las colaboraciones recogidas en el número monográfico dedicado a este asunto por la Journal of Industrial Ecology, Volumen 21, Number 3 (2017). 
expresamente a ella en la Estrategia Temática sobre la prevención y el reciclado de residuos para referirse a la experiencia para entonces ya adquirida en China ${ }^{3}$. Pero todavía no se ha considerado oportuno establecer una definición normativa. No lo hizo, desde luego, la Directiva marco 2008/98/CE, de 19 de noviembre, sobre los residuos (DR), pese a que, aun sin mencionarla, evoca la idea de economía circular al señalar los "objetivos de la política de residuos" que, en última instancia, confluyen en la finalidad de "transformar la UE en una sociedad del reciclado" que trate, por una parte, de "evitar la generación de residuos" y que, por otra, "utilice los residuos como un recurso" (énfasis añadidos). En tal contexto normativo, el significado del concepto hay que deducirlo de una incesante avalancha de documentos políticos (soft law) que enlazan con «Europa 2020-una estrategia para un crecimiento inteligente, sostenible e integrador ${ }^{4} \mathrm{y}$, más precisamente, de los que se orientan hacia la eficiencia en el uso de los recursos (SANTAMARÍA ARINAS, 2016).

El carácter claramente instrumental respecto de esa finalidad se aprecia, por ejemplo, cuando se proclama la voluntad de desplegar "una estrategia destinada a convertir a la UE en una «economía circular» basada en una sociedad del reciclado a fin de reducir la producción de residuos y utilizarlos como recursos" . O cuando se anuncian "las actuaciones necesarias a corto plazo" para "poner en marcha un proceso" al final del cual "deberán haber desaparecido prácticamente los desechos residuales" 6 . Y, desde luego, cuando el Séptimo Programa formula como "Objetivo prioritario $\mathrm{n}^{\circ}{ }^{2}$ " el de "convertir a la UE en una economía hipocarbónica, eficiente en el uso de los recursos, ecológica y competitiva" (énfasis añadido). En él se da a entender que una "economía circular innovadora" es aquella en la que "nada se desperdicia" o, en otras palabras, "en la cual el valor de los productos, los materiales y los

3 Comunicación de la Comisión al Consejo, al Parlamento Europeo y al Comité Económico y Social Europeo y al Comité de las Regiones, [COM(2005) 666 final], que además lleva por antetítulo "[U]n paso adelante en el consumo sostenible de recursos".

4 Bruselas, 3.3.2010. COM (2010) 2020 final.

5 Iniciativa Emblemática «Una Europa que utilice eficazmente los recursos», Bruselas, 26.1.2011. COM (2011) 21 final, p. 7.

6 "Hoja de ruta hacia una Europa eficiente en el uso de los recursos", Bruselas, 20.9.2011. COM (2011) 571 final. 
recursos se mantenga en la economía durante el mayor tiempo posible, y en la que se reduzca al mínimo la generación de residuos"7.

Los pasos posteriores han propiciado un interesante debate entre las instituciones europeas sobre las implicaciones de aquella estrategia en el que las cuestiones conceptuales han quedado en un segundo plano. No obstante, ya en 2014 la Comisión asume el "cambio sistémico completo" que implica la "evolución hacia una economía más circular"; entendiendo por tal aquélla que "mantiene el valor añadido de los productos el mayor tiempo posible y excluye los residuos".

$\mathrm{Y}$, tal vez por aquello de que una imagen vale más que mil palabras, en esa misma Comunicación se inserta el "diagrama conceptual" (un gráfico luego muy divulgado) "que ilustra de forma simplificada las fases principales

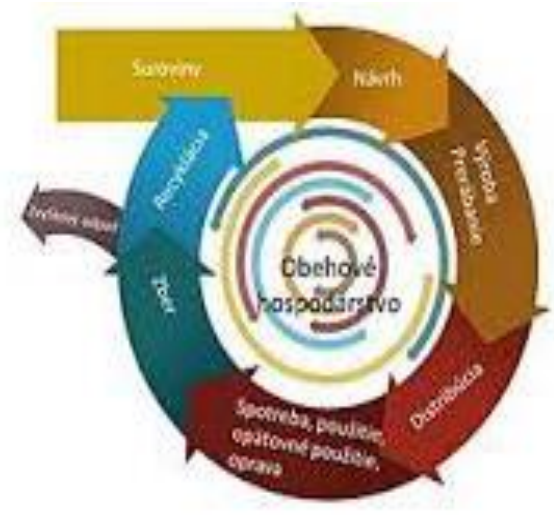
de un modelo de economía circular"8.

El Plan de Acción de 2015 mantiene que "la transición a una economía más circular, en la cual el valor de los productos, los materiales y los recursos se mantenga en la economía durante el mayor tiempo posible, y en la que se reduzca al mínimo la generación de residuos, constituye una contribución esencial a los esfuerzos de la UE encaminados a lograr una economía sostenible, hipocarbónica, eficiente en el uso de los recursos y competitiva" (énfasis añadido). E insiste en que "una transición de este tipo brinda la

7 Decisión 1386/2013, de 20 de diciembre, del Parlamento Europeo y del Consejo, se aprueba el vigente Programa General de Medio Ambiente de la Unión hasta 2020 ("Vivir bien, respetando los límites de nuestro planeta").

8 Comunicación de la Comisión al Parlamento Europeo, al Consejo, al Comité Económico y Social Europeo (CESE) y al Comité de las Regiones (CDR), de 2 de julio de 2014, "Hacia una economía circular: un programa de cero residuos para Europa [Bruselas, 2.7.2014. COM(2014) 398 final]. 
oportunidad de transformar nuestra economía y de generar nuevas ventajas competitivas y sostenibles para Europa"9.

En el despliegue de ese Plan de Acción, los primeros actos legislativos se publicaron a mediados de 2018 (infra 4.3). Entre ellos se encuentra la Directiva 2018/851 que opera 32 modificaciones en la Directiva marco de residuos de 2008 que afectan a 32 previsiones de sus 43 artículos. Sin embargo, pese al énfasis del preámbulo en la vinculación de la reforma con las exigencias de la economía circular, la vigente redacción de la Directiva de residuos sigue sin ofrecer una definición normativa del concepto. Algo que contrasta con su característico conceptualismo máxime cuando sí aborda el problema de la "alineación de definiciones" en aquel sector.

\subsection{Evolución en el ordenamiento jurídico interno}

A escala interna, las iniciativas emprendidas por el Gobierno del Presidente Rajoy se situaban más en el plano social ("Pacto por una Economía Circular") y político que en el jurídico. En febrero de 2018 se difundió el "borrador para información pública" del documento denominado "España circular 2030. Estrategia Española de Economía Circular" que ha sido objeto de merecida crítica doctrinal (PUENTES COCIÑA, 2018). Las iniciativas que el Gobierno del Presidente Sánchez estaba desarrollando para la transposición de las nuevas directivas (para lo que hay plazo hasta el 5 de junio de 2020) quedan por el momento en suspenso con la disolución anticipada de las Cortes Generales. Entre tanto, la economía circular se invoca expresamente en el preámbulo de normas como el Real Decreto 6/2018, de 12 de enero, por el que se crea la Comisión Interministerial para la incorporación de criterios ecológicos en la contratación pública o el Real Decreto 293/2018, de 18 de mayo, sobre reducción del consumo de bolsas de plástico ${ }^{10}$.

9 Comunicación de la Comisión al Parlamento Europeo, al Consejo, al CESE y al CDR, de 2 de diciembre de 2015, "Cerrar el círculo: un plan de acción de la UE para la economía circular [Bruselas, 2.12.2015. COM (2015) 614 final].

10 También se han encontrado retóricas alusiones en el preámbulo de otras normas cuyo articulado poco o nada tiene que ver con las exigencias del concepto como es el caso del Real Decreto-ley 29/2018, de 7 de diciembre, de medidas urgentes para el impulso de la competitividad económica en el sector de la industria y el comercio en España. 
En el panorama autonómico comparado, en cambio, merece ser destacada por muchas razones la Ley del Parlamento de Cataluña 16/2017, de 1 de agosto, del cambio climático (DE LA VARGA PASTOR, 2018). En ella se encuentra por primera vez, y entre otras muchas alusiones de interés, una definición legal del concepto de economía circular en los siguientes términos:

"Economía que promueve la eficiencia en el uso de los recursos para alcanzar un alto nivel de sostenibilidad, mediante el ecodiseño, la prevención y minimización de la generación de residuos, la reutilización, la reparación, la remanufacturación y el reciclaje de los materiales y productos, frente a la utilización de materias primas vírgenes" (artículo 4.d).

Otra aportación relevante llega desde Navarra con la Ley Foral 14/2018, de 18 de junio, de residuos y su fiscalidad (RUIZ DE APODACA ESPINOSA, 2019). En este caso, la novedad apunta, más que a los perfiles del concepto, a su naturaleza jurídica ya que, según su preámbulo, "el título I contiene el objeto, el ámbito de aplicación de la ley foral y los principios de la política y la gestión en materia de residuos, que no son otros que la protección de la salud humana y el medio ambiente; la prevención; quien contamina paga; proximidad y autosuficiencia; información y participación pública; y todo ello de acuerdo con la jerarquía en la gestión de residuos y con los principios de gobernanza y economía circular" (énfasis añadido). De este modo, la economía circular no sólo sería uno de los "objetivos" de la Ley Foral (artículo 1.1) sino también un "principio" que ha de inspirar, cuando menos, la planificación en materia de residuos [artículo 6.1.b)].

Poco después, la Ley $8 / 2018$, de 8 de octubre, de medidas frente al cambio climático y para la transición hacia un nuevo modelo energético en Andalucía, acoge literalmente la definición catalana (apartado $X$ de su Anexo) y requiere el "fomento de la economía circular" en la política de investigación, desarrollo e innovación (artículo 24.2) así como en las determinaciones que ha de contener el Programa de Mitigación de Emisiones para la Transición Energética del Plan Andaluz de Acción por el Clima (artículo 36).

En fin, este recorrido se completa por el momento con dos recientes normas baleares. La primera es la Ley 8/2019, de 19 de febrero, de residuos y suelos contaminados de las Illes Balears que, al igual que el texto navarro, no sólo 
acoge la economía circular como objetivo a promover desde esta política sectorial (artículo 2.1) sino también como "principio" inspirador de sus instrumentos de planificación (artículo 16.1). Y la segunda, la Ley 10/2019, de 22 de febrero, de cambio climático y transición energética de las Islas Baleares, que aporta su propia definición entendiendo por economía circular "una economía en que el valor de los productos y de los materiales se mantiene durante el mayor tiempo posible y la producción de residuos y el uso de los recursos naturales se minimizan, de forma que, cuando un producto o material llega al final de su vida útil, se puede volver a usar y seguir creando valor para la economía y la sociedad, evitando la generación de residuos y el consumo de recursos naturales vírgenes" (artículo 4.d). En esta misma norma se advierte que la economía circular es, a su vez, uno de los componentes del concepto de "transición energética" (infra 3.3).

Como puede apreciarse, las tres definiciones autonómicas por el momento existentes no son del todo coincidentes. La versión balear, más compleja y descriptiva, tiene un marcado carácter técnico. Pero se aparta del patrón que, sin dejar de compartir en lo fundamental su sentido, había establecido el legislador catalán cuya estructura formal ofrece mayor interés para un razonamiento como el que aquí se pretende porque permite vislumbrar mejor el porqué, el para qué y el cómo de la asunción de un concepto jurídico de economía circular.

\section{PRINCIPALES RASGOS CARACTERÍSTICOS DE UN CONCEPTO JURÍDICO EN CONSTRUCCIÓN}

\subsection{Etiología: causas de la juridificación del concepto}

En efecto, el análisis sintáctico de aquella primera definición permite observar que ésta se construye como un sintagma nominal cuyo núcleo es el sustantivo "economía". El complemento del núcleo es una larga proposición subordinada adjetiva que, a su vez, engloba otras dos proposiciones subordinadas adverbiales; una final (pues informa sobre la teleología del concepto) y otra de modo [que describe los medios (metodología) puestos a su servicio]. 
En cuanto al núcleo, según el Diccionario de la Real Academia de la Lengua Española, el sustantivo "economía" procede del griego

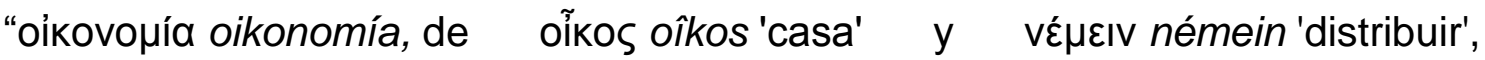
'administrar"' y significa "administración eficaz y razonable de los bienes". Pero cuenta con otras seis acepciones de las cuales las tres primeras son: "conjunto de bienes y actividades que integran la riqueza de una colectividad o un individuo", "ciencia que estudia los métodos más eficaces para satisfacer las necesidades humanas materiales mediante el empleo de bienes escasos" y, ya en sentido figurado, "contención o adecuada distribución de recursos materiales o expresivos". Ofrece además once variantes ${ }^{11}$ entre las que no aparece la de "economía circular" pero sí la de "Economía política" cuyo significado hay que completar acudiendo a otras fuentes que le atribuyen el de "ciencia que trata de la producción, distribución y consumo destinados a satisfacer las necesidades humanas"12.

El vocablo muestra, por tanto, un alto grado de polisemia puesto que sirve para designar al menos tres realidades diferentes que son a) los bienes $y$ actividades en sí mismos considerados; b) su administración, que necesariamente ha de ser "eficaz y razonable" y c) la rama de las ciencias sociales que se ocupa de todo ello. $Y$ el caso es que en la definición que se analiza nada indica que el complemento del núcleo no pueda o incluso deba ir referido conjunta y simultáneamente a todas ellas. Si el hablante no hubiera querido abarcar tanto, debería haber utilizado un sustantivo más preciso, tal vez menos pretencioso, que el de "economía". En todo caso, resulta evidente que tal complemento sintáctico encierra una novedad conceptual (los atributos de la "circularidad") y cabe preguntarse cuál es la causa de que tal novedad se haya considerado necesaria.

Se ha de recordar, en este sentido, que, compartiendo aquella misma raíz

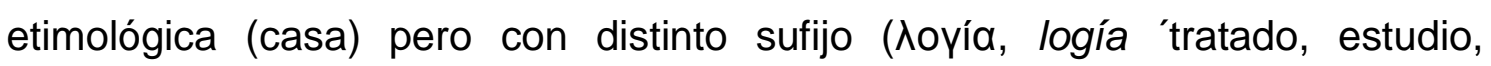
ciencia'), por "ecología" se entiende la "ciencia que estudia los seres vivos como habitantes de un medio, y las relaciones que mantienen entre sí y con el

11 Que son las de "economía animal", "economía cerrada", "economía de escala", "economía de mercado", "economía del bienestar", "economía dirigida", "economía mixta", "economía planificada", "economía sumergida", "economías externas" y "economía política".

12 M. MOLINER, Diccionario de uso del español, Gredos, Madrid, 1990. 
propio medio". Su segunda y única acepción es "medio ambiente" que, según el Diccionario de la RAE, es el "conjunto de circunstancias exteriores a un ser vivo". Se diría, pues, que, en términos léxicos, no puede haber economía sin ecología porque la semántica presupone necesariamente el conocimiento de la "casa" para su "eficaz y razonable" administración. En efecto, dentro de ese conjunto de circunstancias exteriores al ser humano se encuentran los recursos naturales (bienes escasos que integran la riqueza de la sociedad) indispensables para las actividades que pretenden satisfacer las necesidades humanas materiales. En la práctica, sin embargo, no parece que su administración esté siendo eficaz, razonable ni contenida. Baste reparar al efecto en los estudios que evidencian el ritmo de agotamiento de muchos elementos de la tabla periódica o los resultados de la aplicación de la metodología de la huella ecológica (BACKES, 2017).

De este convencimiento surge, como es bien sabido, la noción postmoderna de "desarrollo sostenible" con la que la comunidad internacional asume, no sin detractores, el compromiso global de transformar el modelo de crecimiento económico imperante en la década de los ochenta del pasado siglo por otro que permita satisfacer las necesidades del presente sin comprometer la satisfacción de las necesidades de las generaciones futuras. Un compromiso que se renueva periódicamente y que hoy se plasma al más alto nivel en los Objetivos del Desarrollo Sostenible de la Agenda 203013. Pero la retórica política no basta para acomodar la Economía real -ni la ciencia que la estudia que sigue basada en parámetros anticuados, puramente cuantitativos, como el producto interior bruto (PIB)- a las exigencias cualitativas requeridas por los otros dos pilares (social y ambiental) de la sostenibilidad (PILLING, 2019) ${ }^{14}$.

13 A partir de las previsiones de la Declaración de la Asamblea General de la ONU adoptada en Río de Janeiro el 27 de julio de 2012 (Río+20), se encuentran en la Resolución de la Asamblea General de Naciones Unidas A/70/1, adoptada el 27 de septiembre de 2015 y titulada "Transformar nuestro mundo: la Agenda 2030 para el Desarrollo Sostenible" que contiene los 17 "Objetivos del Desarrollo Sostenible" (ODS) con sus correspondientes "metas", que resultan ser 169. Téngase en cuenta también el "Marco de indicadores mundiales" que, tras los trámites allí previstos, fue aprobado finalmente por Resolución de la Asamblea General de 6 de julio de 2017.

14 En otro trabajo divulgativo de este mismo autor, publicado en el El País de 3 de febrero de 2019 bajo el título "EI PIB y su grave error de cálculo", se explica que con "el culto al PIB" que domina "el pensamiento económico" desde hace 80 años "nos hemos convertido en esclavos de una definición sesgada y restrictiva de lo que la economía significa de verdad". 
Entre tanto, en diferentes foros no han dejado de aparecer neologismos como los de economía ecológica, economía verde, economía hipocarbónica o bioeconomía a las que viene a sumarse el de economía circular (JIMÉNEZ HERRERO, 2012). Y, aunque comparten un campo semántico crecientemente poblado, se supone que no son sinónimos sino que cada uno de ellos aporta al núcleo que comparten significados nuevos pero compatibles ${ }^{15}$. Puestos a descubrir el valor añadido de los atributos de la circularidad cabe observar que éstos se formulan "frente a la utilización de materias primas vírgenes". Esta expresión contrasta con la de "materias primas secundarias" sobre la que se volverá infra 4.4. Pero, por el momento, cabe sostener que, desde el punto de vista etiológico, la economía circular sería una reacción frente a la "economía lineal", noción que tampoco aparece recogida en el Diccionario, pero que, según la literatura especializada, se caracteriza por "extraer, fabricar, consumir y tirar"; es decir, por el despilfarro que supone la extracción masiva de materias primas, los procesos tecnológicos existentes para su transformación, el consumo acelerado de los productos así obtenidos y la ingente cantidad resultante de residuos que se desperdician.

Sin embargo, junto a esta causa estructural, que durante lustros prácticamente no había desplegado efectos prácticos, podría también señalarse una causa coyuntural que, coincidiendo con las turbulencias de la primera gran crisis económica del siglo XXI, ha venido finalmente a favorecer la juridificación del concepto en un contexto de políticas de austeridad. Se trata, como consta expresamente en el Séptimo Programa, del reconocimiento por las autoridades europeas de la necesidad de "reducir la dependencia de las importaciones de materias primas" $\mathrm{y}$, en particular, de las denominadas "materias primas críticas" (tierras raras, fósforo, cobalto o silicio, entre otras que se incluyen en una Lista que actualiza la Comisión). Una forma, si se quiere, de hacer de la necesidad virtud en un mercado global cada vez más inestable.

\subsection{Teleología: un objetivo político relativamente transformador}

15 Un ejemplo de simbiosis conceptual puede encontrarse en la expresión "bioeconomía circular" que utiliza el Acuerdo de 18 de septiembre de 2018 del Consejo de Gobierno por el que se aprueba la Estrategia Andaluza de Bioeconomía Circular (BOJA de 24 de septiembre de 2018). 
Volviendo a la definición objeto de análisis, interesa ahora considerar para qué se crea esta nueva locución. A ello responde la primera proposición del complemento del núcleo que se abre precisando que ésta es una economía "que promueve la eficiencia en el uso de los recursos para alcanzar un alto nivel de sostenibilidad". Empezando por esto último, cabe pensar que la economía circular se concibe como un medio más al servicio de un fin principal que es "alcanzar un alto nivel de sostenibilidad" (respondiendo así a la causa estratégica). Y que su aportación radica en promover la eficiencia en el uso de los recursos (supra 2.1). El Diccionario de uso del español explica que "eficiencia" es la "cualidad de eficiente" que es sinónimo de "eficaz". Ambos adjetivos "se aplican a lo que realiza cumplidamente la función a que está destinado" pero María Moliner advierte que "eficaz se aplica más a cosas mientras que eficiente se aplica más a personas u organismos". El legislador autonómico no se atiene a este rigor lingüístico porque, en realidad, está empleando tecnicismos que provienen del ámbito empresarial donde la "eficacia" consiste en alcanzar las metas establecidas mientras que la "eficiencia" entraña lograr esas metas con la menor cantidad de recursos.

El matiz es importante porque permite enlazar este esfuerzo conceptual con corrientes de pensamiento que vienen abogando por "hacer más con menos" e, incluso, con la desmaterialización de la economía ${ }^{16}$. En este sentido, comparte espacio con la noción de "eficiencia energética" que hace tiempo encontró acomodo en el discurso jurídico. Pero viene a completarla porque la eficiencia en el uso de recursos acoge también el ahorro de materiales. De hecho, tomando como referencia el funcionamiento de los ecosistemas naturales, obliga a atender a los "flujos de materiales" a lo largo de toda la cadena de valor de los productos (véase figura adjunta) superando el enfoque "de la cuna a la tumba" por el de "de la cuna a la cuna" (GUDín, 2018). Y, de este modo, a "preservar y aumentar el capital natural, controlando los stocks finitos y equilibrando los flujos de recursos renovables" (CERDÁ y KHALILOVA, 2016). Se notará que aquí adquiere sentido la superación de la tradicional expresión

16 Así, por ejemplo, de "círculo virtuoso", al que se aspira para "crear más valor con menos recursos", hablaba ya la Comunicación de la Comisión al Parlamento Europeo, al Consejo, al Comité Económico y Social Europeo y al Comité de las Regiones, de 25 de junio de 2008, relativa al Plan de Acción sobre Consumo y Producción Sostenibles y una Política Industrial Sostenible [COM(2008) 397 final - no publicada en el Diario Oficial; énfasis añadido]. 
de "patrimonio natural" (limitada a la protección de la biodiversidad) por la más moderna de "capital natural" (referida ya al conjunto de los recursos disponibles, o lo que es lo mismo, a la "economía" en la primera de las tres acepciones que han quedado reflejadas supra 3.1).

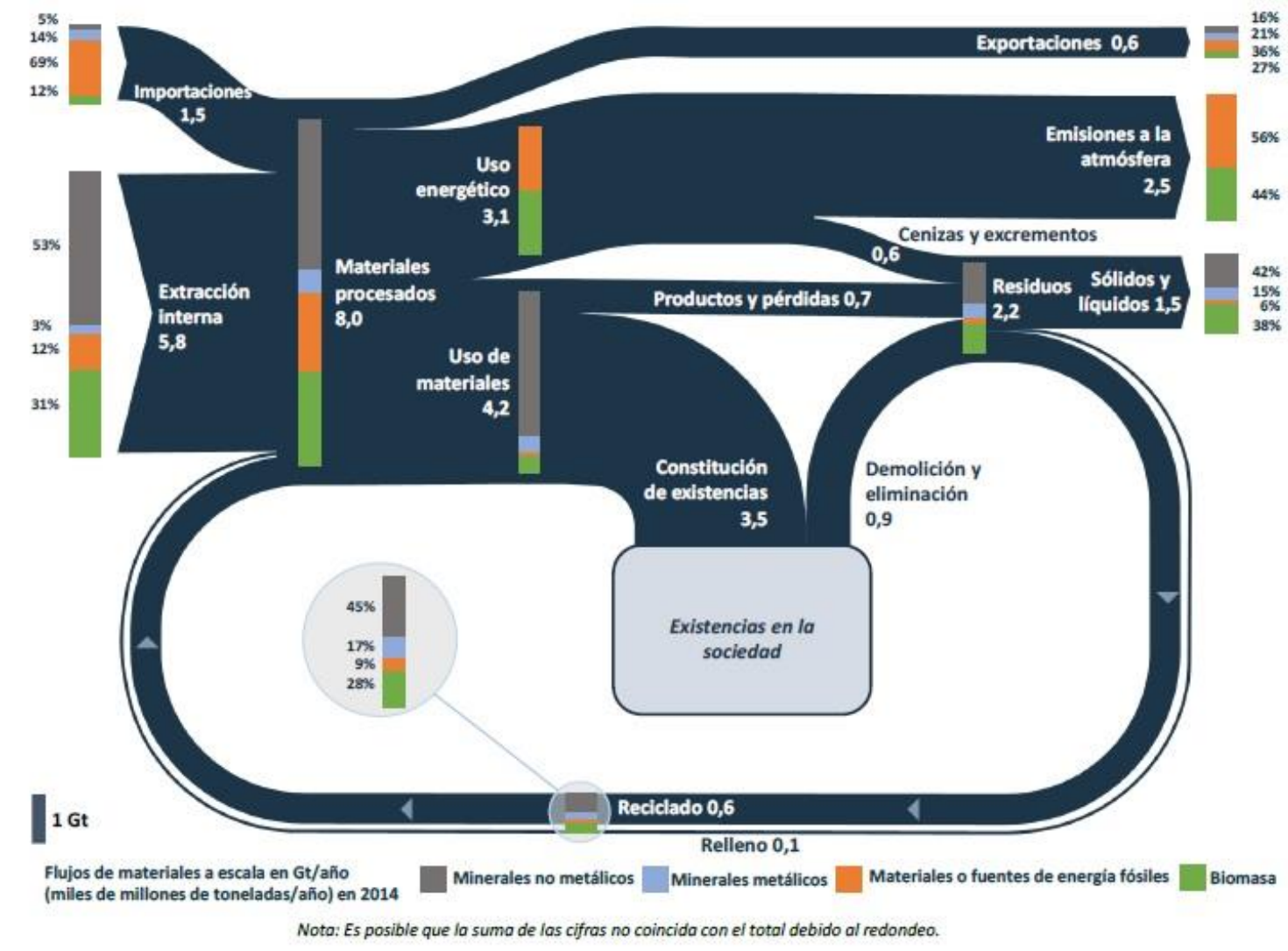

Ilustración 1: Flujos de materiales en la economía (EU-28, 2014)9, 10

FUENTE: Comunicación "marco de seguimiento para la economía circular" [COM(2018) 29 final, p. 3].

Con todo, no debe pasar desapercibido que esta parte de la definición emplea el verbo "promover" que es "impulsar el desarrollo o la realización de algo". Puede decirse entonces que, a salvo de experiencias de escala local con mayor o menor alcance, la economía circular no existe sino que es "algo" todavía por conseguir: transformar las tres realidades apuntadas (los recursos, su administración y el conocimiento existente sobre todo ello) para "extraer el máximo valor y uso de todas las materias primas, productos y residuos"17. Pero conviene advertir que el fin así formulado puede ser más o menos ambicioso porque no es lo mismo abogar por cerrar el círculo -para lo que, en principio,

$17 \operatorname{COM}(2018) 32$ final, p. 1. 
podría bastar con aprovechar los recursos y la energía presentes en los residuos y reincorporarlos continuamente en los ciclos económicos- que postular que la economía circular sería "un método que busca no sólo una producción sostenible, sino un consumo responsable" (GARCÍA GARCÍA, $2018)^{18}$.

Entre ambas posiciones existe, pues, una amplia gama de opciones para elegir en la toma de las decisiones que hay que adoptar para acabar convirtiendo el fin en concretos objetivos políticos a lograr en un tiempo y lugar dados. $Y$ aunque pueda parecer sutil, esa distinción entre fin (estratégico) y objetivos (tácticos) resulta relevante en términos jurídicos donde esa conversión apela usualmente a técnicas de planificación en las que, a partir de un diagnóstico de la situación de partida, suelen combinarse escalas y factores diversos como, por ejemplo, el porcentaje de eficiencia material perseguido (que puede ir desde el 1 hasta el 100 por cien) o el horizonte temporal previsto para alcanzarlo (a corto, a medio o a largo plazo ${ }^{19}$ ).

Más aún, asumido el fin estratégico en cuestión, la determinación de los objetivos políticos con él vinculados se presta a un debate ideológico en el que se ha llegado a sugerir que "sería preciso repensar el propio capitalismo y encarar sus problemas estructurales" (NORONHA, 2017). Por descontado, no es eso lo que se propone la Unión Europea que, si aspira a "una economía más circular", lo hace sin cuestionar en absoluto la Economía de mercado. No obstante, en un contexto claramente marcado por fuerzas (neo)liberales, en su seno también se aprecian ciertas discrepancias entre las posiciones más conservadoras que viene manteniendo el Consejo (basadas fundamentalmente en postulados de tecno-innovación para la fase de producción) y las más progresistas de otras instituciones (partidarias de intervenir más resueltamente

18 En este último sentido, desde una perspectiva crítica frente a la concepción de la economía circular como "an engineering system" limitado a la generalización de prácticas de reutilización, reciclado y remanufacturación, se ha objetado que "[W]hat is truly required to reduce environmental impact is less production and less consumption. The circular economy promises this outcome, but, once economic realities are considered, may fail to deliver on its potential" (ZINK y GEYER, 2017; énfasis añadido).

19 Que es, precisamente, la opción asumida por la UE como corrobora la presentación del "marco de seguimiento para la economía circular" cuando explica que "los resultados de este seguimiento deben constituir la base para establecer nuevas prioridades en pos del objetivo a largo plazo de una economía circular" [COM(2018) 29 final, p.1; énfasis en el original]. 
también en la fase de consumo) como el Parlamento Europeo o el Consejo Económico y Social Europeo (HANNEQUART, 2016). Estas tensiones podrían explicar la actitud posibilista de la Comisión Europea que, tras retirar su primer "paquete" de 2014, consiguió sacar adelante un segundo Plan de Acción que se reputó menos ambicioso.

Aun así, los objetivos de este Plan se siguen presentando como todo un "cambio sistémico" que requiere, a su vez, transformaciones más allá de lo puramente económico puesto que la eficiencia en el uso de los recursos no llegará con el mero juego espontáneo de las fuerzas de la oferta y la demanda en el mercado. $\mathrm{Y}$, lógicamente, si esto es así, parece que, en cuanto instrumento indispensable para ordenar cambios sociales de semejante envergadura $^{20}$, el Derecho no puede quedar al margen de tales transformaciones.

\subsection{Metodología: ¿un principio sectorial o general?}

Cuestión diferente es el alcance que hayan de tener las transformaciones jurídicas requeridas. A este respecto, la última proposición de la definición considerada indica que, "frente a la utilización de materias primas vírgenes", el fin perseguido se ha de promover "mediante" una serie de actividades económicas que son "el ecodiseño, la prevención y minimización de la generación de residuos, la reutilización, la reparación, la remanufacturación y el reciclaje de los materiales y productos". Parece que con esta enumeración cerrada de nociones técnicas el legislador invita al jurista a centrar su atención en una concepción limitada y estática de la economía circular.

En efecto; sorprende un tanto que, puestos a enumerar actividades, no se haya recurrido a una lista abierta que permitiría su ampliación si fuera necesaria. Por lo demás, aunque las palabras "ecodiseño" y "remanufacturación" no se encuentran en el Diccionario, ninguna de esas actividades resulta desconocida

20 En su Dictamen sobre la Comunicación COM(2018) 29 final (DOUE C 367, de 10 de octubre de 2018, el CESE apela a la "gran importancia" que reviste "la cultura circular, basada en el replanteamiento de los valores y en el cambio de los patrones de consumo actuales". De "revolución cultural" Ilega a hablar en su Dictamen sobre la "Estrategia Europea para el plástico en una economía circular" [Comunicación COM(2018)] (DOUE C 283, de 10 de agosto de 2018). 
ni carece tampoco de regulación previa. Desde una óptica jurídica podría pensarse, por tanto, que no se requieren cambios normativos sino, más bien, la efectiva aplicación de la legislación preexistente tanto en materia de productos como en materia de residuos. Así, en este último sector normativo, como es sabido, rige desde hace décadas el principio de jerarquía de opciones que da preferencia a la prevención frente a la gestión y, dentro de ésta, a la valorización (que engloba cualquier operación que permita aprovechar energía o recursos contenidos en los residuos) frente a la "eliminación". No es cuestión de insistir aquí en la importancia práctica que revisten los problemas terminológicos vinculados a la "jerga del residuo" (SANTAMARÍA ARINAS, 2018a). Baste indicar, en tal sentido, que muchos de esos conceptos, incluyendo los esenciales de residuo, valorización y eliminación, deberían probablemente reconsiderarse en el nuevo contexto de la economía circular (DE SADELEER, 2017). Y que, entre tanto, adquiere carta de naturaleza la noción de "valorización material" para designar opciones de gestión (como la reutilización o el reciclado) que tienen preferencia frente a la "valorización energética" (incineración) ${ }^{21}$.

Por este camino se acaba llegando a la conclusión de que es necesario, por supuesto, aplicar debidamente la legislación vigente pero también perfeccionarla e incluso completarla con disposiciones nuevas. En efecto, pese a las limitaciones de la definición hasta aquí considerada, el articulado de la propia Ley catalana confirma esta impresión al menos por lo que se refiere tanto al ecodiseño ${ }^{22}$ como a los residuos ${ }^{23}$. Y otras normas autonómicas invitan

21 La aportación es puramente terminológica pues la preferencia rige desde que el principio de jerarquía de opciones se desglosa en cinco niveles con la Directiva de 2018. Pero se encuentra, por ejemplo, en la Ley balear 10/2019 que, con evidente inspiración en el precepto catalán equivalente, matiza que "en el sector de los residuos" se avanzará, entre otras cosas, en "la sustitución de materias primas por subproductos o materiales procedentes de la valorización material de residuos para favorecer la creación de una economía circular y la reducción de emisiones derivadas de la extracción y transformación de materias primas" [DA6 $\left.{ }^{a} .2 . e\right) ;$ énfasis añadido].

22 Dentro de las "políticas sectoriales", al ocuparse de "industria, servicios y comercio", el artículo 20.3 de la Ley 16/2017 dice que "deben impulsarse las modificaciones legislativas necesarias con relación a la promoción del ecodiseño y la lucha contra la obsolescencia programada, de acuerdo con las directrices de la Unión Europea" (énfasis añadidos).

23 El artículo 22.e) de la misma norma dice que "las medidas que se adopten en materia de residuos deben ir encaminadas a reducir la vulnerabilidad de la población y las emisiones de gases de efecto invernadero, priorizando la estrategia de residuo cero a fin de ahorrar material y de reducir su procesamiento, especialmente en la reducción y penalización de los productos 
a extenderla a más campos como los de la política de investigación, desarrollo e innovación o las estrategias de "transición energética"24. De este modo se comprueba que, por modestos que fueren, los objetivos transformadores vinculados con la economía circular tienen necesariamente un carácter transversal y, al mismo tiempo, abierto 0 , si se quiere, dinámico pero gradual y progresivo. En términos jurídicos, estos rasgos le confieren vocación expansiva y sugieren su posible consideración como un principio general del Derecho no ceñido exclusivamente al sector de los residuos, como ya han reconocido los legisladores navarro y balear (supra 2.2), sino generalizable al conjunto del Derecho ambiental ${ }^{25}$ e incluso a la totalidad del Derecho público ${ }^{26}$ cuando no también a ciertas parcelas del Derecho privado como las que rigen las relaciones entre particulares en materia de consumo.

\section{EL ALCANCE DE LAS PRIMERAS TRANSFORMACIONES JURÍDICAS REQUERIDAS}

La legislación interna hasta aquí considerada contiene remisiones a la normativa europea que permiten confirmar definitivamente tanto el carácter transversal como el carácter gradual del concepto jurídico de economía

envasados con un uso intensivo de combustibles fósiles, y concretamente deben ir encaminadas a", entre otras cosas, "la sustitución de materias primas por subproductos o materiales procedentes de la valorización de residuos para favorecer la creación de una economía circular" (énfasis añadidos). Pero la Disposición final octava dice que "el Gobierno debe presentar al Parlamento, en el plazo de dos años a contar desde la entrada en vigor de la presente ley, un proyecto de ley de prevención de los residuos y de uso eficiente de los recursos, como ley marco que ampare los cambios legislativos necesarios para avanzar hacia una economía circular, baja en carbono y basada en la sostenibilidad, la producción limpia, la responsabilidad ampliada del productor y el residuo cero" (énfasis añadidos).

24 El artículo 4 de la Ley balear 10/2019 define "transición energética" como "el paso a un sistema energético cuya finalidad última es garantizar su sostenibilidad. Este sistema se caracteriza por el uso de energías renovables, la eficiencia energética, el uso eficiente de recursos naturales mediante la introducción de una economía circular, el desarrollo sostenible, la movilidad sostenible, y la justicia, la democratización, la descentralización de la energía y el estímulo a la producción local a efectos de simplificar la logística y su impacto ambiental (énfasis añadido).

25 Nótese que entre los "principios informadores de la autorización ambiental integrada" ya figura el de que "se utilice la energía, el agua, las materias primas y otros recursos de manera eficiente" [artículo 4.1.c) TRLPCIC].

26 Para lo que bastaría dar por supuesta la exigencia de eficiencia material dentro del mandato de "velar por la utilización racional de todos los recursos naturales" que el principio rector del artículo $45 \mathrm{CE}$ dirige al conjunto de los Poderes Públicos. Y, aun a otra escala, en el principio de eficacia que rige la actuación de las Administraciones Públicas (artículo 103.1 CE). 
circular. Basta para ello reparar en el contenido y en el horizonte temporal del vigente Plan de Acción de la UE para la economía circular ${ }^{27}$. Con un tono que pretende ser persuasivo, esta Comunicación resalta los "beneficios" que de ella se esperan como son los de "proteger a las empresas contra la escasez de recursos y la volatilidad de los precios", "contribuir a crear nuevas oportunidades empresariales", "puestos de trabajo" y "oportunidades para la integración y la cohesión social". También "ahorrará energía" y "contribuirá a evitar daños irreversibles". Tras reconocer el papel "fundamental" que han de jugar los "agentes económicos" y el resto de "autoridades", se indica que el "objetivo" de la intervención de la UE es "garantizar que se disponga del marco normativo adecuado para el desarrollo de la economía circular en el mercado único, y transmitir señales claras a los operadores económicos y a la sociedad en general sobre el camino que ha de seguirse respecto de los objetivos de residuos a largo plazo, así como un conjunto de acciones concretas, amplias y ambiciosas que se llevarán a cabo antes de 2020" (énfasis añadido). Cabe esperar, por tanto, que a partir de esa fecha, que es también la de vencimiento del Séptimo Programa, este Plan sea sustituido por otro que podrá ser más o menos ambicioso dependiendo en gran medida (elecciones al Parlamento Europeo mediante), de la voluntad política que hasta ahora, no sin fluctuaciones, ha venido impulsando lo que siempre se ha entendido como un proceso de transición.

Entre tanto, el "Plan de acción" propiamente dicho se estructura en siete apartados y se completa con un Anexo en el que aparece una tabla resumen con dos columnas en las que figuran las "acciones" propuestas para cada uno de ellos con su respectivo "calendario". No es objeto de este trabajo describir tales acciones ni valorar su despliegue hasta el momento. Desde la óptica conceptual aquí asumida se trata, más bien, de señalar las principales áreas del Derecho que, en mayor o menor medida, ya se están viendo afectadas por ese principio emergente de economía circular. Se seguirá para ello la estructura de las fases de la "cadena de valor" que emplea el propio Plan de acción. Por no entrañar ninguna propuesta de carácter normativo no se van a

27 Comunicación de la Comisión al Parlamento Europeo, al Consejo, al CESE y al CDR, de 2 de diciembre de 2015, "Cerrar el círculo: un plan de acción de la UE para la economía circular [Bruselas, 2.12.2015. COM (2015) 614 final]. 
comentar aquí el resto de las acciones del Plan que versan sobre las consideradas "áreas prioritarias", sobre "innovación e inversiones" ni sobre su "seguimiento"28.

\subsection{Producción}

\begin{tabular}{|c|c|}
\hline roducción & \\
\hline Acciones & Calendario \\
\hline $\begin{array}{l}\text { Hacer hincapié en los aspectos de la economía circular en los futuros } \\
\text { requisitos de los productos en el marco de la Directiva sobre diseño } \\
\text { ecológico }\end{array}$ & A partir de 2016 \\
\hline $\begin{array}{l}\text { Plan de trabajo sobre diseño ecológico } 2015-2017 \text { y solicitud a las } \\
\text { organizaciones europeas de normalización para que elaboren normas } \\
\text { sobre la eficiencia de los materiales con vistas al establecimiento de futuros } \\
\text { requisitos de diseño ecológico sobre la durabilidad, la reparabilidad y la } \\
\text { reciclabilidad de los productos }\end{array}$ & $\begin{array}{l}\text { Diciembre } \\
2015\end{array}$ \\
\hline $\begin{array}{l}\text { Propuesta de Reglamento de Ejecución relativo a televisores y } \\
\text { visualizadores }\end{array}$ & $\begin{array}{l}\text { Finales de } 2015 \\
0 \text { principios de } \\
2016\end{array}$ \\
\hline $\begin{array}{l}\text { Estudiar opciones y acciones para establecer un marco político más } \\
\text { coherente de las distintas líneas de trabajo de la política de productos de la } \\
\text { UE en su contribución a la economía circular }\end{array}$ & 2018 \\
\hline $\begin{array}{l}\text { Incluir orientaciones sobre la economía circular en los documentos de } \\
\text { referencia sobre las mejores técnicas disponibles (BREF) para varios } \\
\text { sectores industriales }\end{array}$ & A partir de 2016 \\
\hline $\begin{array}{l}\text { Orientación y promoción de las mejores prácticas en los planes de } \\
\text { gestión de residuos mineros }\end{array}$ & 2018 \\
\hline $\begin{array}{l}\text { Establecer una red abierta y paneuropea de infraestructuras } \\
\text { tecnológicas para las pymes al objeto de integrar las tecnologías } \\
\text { avanzadas de fabricación en sus procesos de producción }\end{array}$ & 2016 \\
\hline $\begin{array}{l}\text { Examinar cómo mejorar la eficiencia y la penetración del sistema de } \\
\text { gestión y auditoría medioambientales (EMAS) y del programa piloto sobre } \\
\text { verificación de la tecnología ambiental (ETV) }\end{array}$ & 2017 \\
\hline
\end{tabular}

28 No obstante, puede accederse al texto completo de dicho Anexo en http://www.pru2030araba.eus/wp-content/uploads/2017/02/3.-Cerrar-el-c\%C3\%ADrculo.-Unplan-de-acci\%C3\%B3n-de-la-UE-para-la-Econom\%C3\%ADa-Circular.-Anexo.pdf (último acceso, 15 de abril de 2019). 
Desarrollar una mejor base de conocimientos y el apoyo a las pymes \begin{tabular}{|l|l}
\hline para sustituir las sustancias peligrosas extremadamente preocupantes & 2018
\end{tabular}

FUENTE: Anexo del Plan de acción de la UE para la economía circular" [COM(2015) 614 final; énfasis en el original].

La "cadena de valor" acaba enlazando el Derecho de los residuos con el Derecho de los productos, aunque, en realidad, nunca han sido dos compartimentos estancos. Desde 2001 la denominada "política integrada de productos" (HANNEQUART, 2016) ya había sugerido un enfoque de "ciclo de vida" que tuviera en cuenta, entre otras cosas, por decirlo con las palabras que emplea el Séptimo Programa, su durabilidad, reparabilidad, posibilidad de reutilización y reciclabilidad. El análisis del ciclo de vida, para el que existen métodos de análisis estandarizados (ISO 14040:2006 y 14044:2006), es útil para el diseño de cualquier tipo de producto o actividad (LETÓN GARCÍA, 2018, 347-363). Pero el Plan de acción centra su atención en lo que se conoce como diseño ecológico cuya regulación hasta el momento se limita a los productos relacionados con la energía. Hay, por tanto, amplio margen para avanzar en este campo en la doble dimensión de ampliar el ámbito de aplicación inicial para acoger otras gamas de productos y de someter todos ellos no sólo a exigencias de eficiencia energética sino también a criterios de eficiencia en el uso de recursos ${ }^{29}$.

Por lo demás, el Derecho de los productos no sólo abarca el ecodiseño sino que en él confluyen subsectores normativos muy diversos que en su origen atienden a finalidades específicas como las de sanidad, seguridad y calidad pero en las que es factible integrar también criterios de eficiencia material. Muchos de ellos condicionan tanto el régimen de los "procesos de

29 Así se refleja en el Considerando 36 del Reglamento (UE) 2017/1369 del Parlamento Europeo y del Consejo de 4 de julio de 2017 por el que se establece un marco para el etiquetado energético y se deroga la Directiva 2010/30/UE: "La Comisión debe presentar un plan de trabajo a largo plazo para la revisión de las etiquetas de productos determinados relacionados con la energía que incluya una lista indicativa de otros productos relacionados con la energía respecto a los cuales se podría establecer en el futuro una etiqueta energética. La aplicación del plan de trabajo partirá de un análisis técnico, ambiental y económico de los grupos de productos de que se trate. Ese análisis debe examinar también la información complementaria, concretamente la posibilidad, y el coste, de facilitar a los consumidores información sobre el rendimiento de un producto relacionado con la energía, como su consumo energético, su durabilidad o su comportamiento ambiental, en consonancia con el objetivo de promover una economía circular. Esa información complementaria debe mejorar la inteligibilidad y eficacia de la etiqueta de cara a los consumidores y no debe tener ningún impacto negativo en los consumidores" (énfasis añadidos). 
producción" de bienes como la prestación de algunos servicios. Baste pensar, al respecto, en las prohibiciones y limitaciones del uso de sustancias peligrosas en la fabricación y comercialización de productos que impone el Reglamento REACH (RÖMPH y VAN CALSTER, 2018), cuya efectiva aplicación también a los productos importados es decisiva para asegurar desde el primer momento "ciclos de materiales no tóxicos"30. O en las especificaciones resultantes de fórmulas de autorregulación que se plasman en normas técnicas y en procesos de certificación de productos industriales y agrarios e incluso de ciertos servicios.

En uno de los sistemas de autorregulación regulada más conocidos, que es el de gestión y auditoría medioambiental (EMAS), la integración avanza sin esperar a la anunciada modificación del articulado del Reglamento 1221/2009 gracias a los Documentos Sectoriales de Referencia (DRS) que han empezado a aparecer a partir de $2015^{31}$. Para cada sector considerado estos DRS especifican las "mejores prácticas de gestión medioambiental" (MPGA) con sus respectivos "indicadores sectoriales de comportamiento medioambiental" y "parámetros comparativos de excelencia". Con ellos existen por fin, y a diferencia de lo que venía ocurriendo hasta ahora, criterios sustantivos que condicionan la elección y, en cierto modo, la intensidad de los compromisos que las organizaciones decidan asumir para cada ciclo de auditoría (SANTAMARÍA ARINAS, 2012). Así, por ejemplo, en uno de los más recientes se lee que "[D]ada la variedad de actividades realizadas por las diferentes administraciones públicas en toda la Unión, el documento de referencia sectorial correspondiente debe centrarse en los problemas ambientales claves para el sector. Debe identificar, a modo de mejores prácticas de gestión medioambiental, medidas concretas para mejorar la gestión administrativa, la eficiencia energética y la eficiencia en el uso de los recursos, la movilidad, el

30 Puede verse, al respecto, el debate interinstitucional suscitado por la Comunicación de la Comisión sobre la aplicación del paquete sobre la economía circular: opciones para abordar la interfaz entre las legislaciones sobre sustancias químicas, sobre productos y sobre residuos [COM(2018) 32 final].

31 El primero de aquellos "documentos" se refiere al sector del comercio (Decisión 2015/801). Con posterioridad han aparecido los DRS relativos al turismo (Decisión 2016/611), a la producción de alimentos y bebidas (Decisión 2017/1508), al sector agrícola (Decisión (UE) 2018/813), al sector de la Administración Pública (Decisión 2019/61), el sector de la fabricación de automóviles (Decisión 2019/62) y al sector de la fabricación de aparatos eléctricos y electrónicos (Decisión 2019/63). 
uso del suelo, la calidad del aire, el suministro de agua y la gestión de aguas residuales, con miras a fomentar una economía más circular" (énfasis añadido). Esta fórmula se ha convertido en una especie de cláusula de estilo que se reitera, con las adaptaciones precisas, para cada sector. Pero sin duda el DRS más avanzado es el relativo al sector de los aparatos eléctricos y electrónicos que incluye su propio cuadro de "flujos de materiales" $y$, sin dejar de integrar en otras el enfoque ciclo de vida, desgrana cuatro MPGM específicas "que promueven una economía más circular"32.

Ciertamente, EMAS es un sistema voluntario pero por esta vía enlaza con técnicas clásicas de intervención administrativa como las evaluaciones ambientales (EAE y EIA) y, sobre todo, la autorización ambiental integrada (AAI). En realidad, las normas que rigen a este respecto son anteriores al Plan de Acción y no emplean la palabra economía circular pero de un modo u otro en todas ellas había referencias que posibilitaban tener en cuenta en su aplicación el "uso racional de los recursos" con criterios de eficiencia material. Sin ir más lejos, la "eficiencia en la ocupación del suelo" debería ser un componente fundamental en la evaluación de la sostenibilidad territorial de los planes [artículo 2.2.c) TRLS] y no sólo por constituir el suelo un recurso natural escaso sino también por las implicaciones de su ordenación para el "ecosistema urbano" (BUSTILLO BOLADO, 2018). Y, aunque a veces pasa desapercibido, alguna consecuencia tendría que tener en la EIA de proyectos que el estudio de impacto ambiental deba contener "previsiones relativas a la utilización de recursos naturales" (artículo 35 y Anexo VI LEA). O que la solicitud de AAI deba contener referencia a los "recursos naturales, materias primas y auxiliares, sustancias, agua y energía empleados o generados en la instalación" [artículo 12.1.a).4ํㅜㄴ TRLPCIC].

A esta misma relectura se presta el Anexo III TRLPCIC cuando alude, por ejemplo, al "consumo y naturaleza de las materias primas" entre los "[A]spectos que deben tenerse en cuenta" para determinar las mejores técnicas disponibles. De hecho, como es sabido, en una primera etapa el legislador

32 "Orientación estratégica sobre el diseño de productos para la economía circular", "Oferta de servicios de productos integrados", "Remanufactura o reacondicionamiento de alta calidad de productos usados" y "Aumento del contenido de plásticos reciclados en aparatos eléctricos y electrónicos". 
europeo consintió una aplicación flexible de la "cláusula MTD". Pero desde 2010 reforzó su papel puesto que, si bien los "documentos técnicos de referencia" (BREFs) siguen careciendo de fuerza vinculante por sí mismos, sus contenidos principales adquieren efecto jurídico al tener que recogerse en las "conclusiones sobre las MTD" que se han de ir aprobando mediante Decisión de la Comisión. Así, en esta dinámica abierta al avance científico y técnico, entre las más recientes cabe mencionar, por ejemplo, las Decisiones relativas a la cría intensiva de aves de corral o de cerdos, a la industria química orgánica de gran producción, a las grandes instalaciones de combustión o a las instalaciones de gestión de residuos. $Y$ el caso es que en tales Decisiones empieza a ser habitual la incorporación de MTDs que obligan a "monitorizar el consumo anual de agua, energía y materias primas", que concretan la "eficiencia en el uso de materiales" o que prescriben "maximizar la reutilización de envases" y "reducir la cantidad de residuos destinados a la eliminación"33. De este modo, con el artículo 22.1.a) TRLPCIC esas MTD "pasan a ser parte del condicionado obligatorio de la AAl" (FORTES MARTíN, 2018).

\subsection{Consumo}

\begin{tabular}{|c|c|}
\hline Consumo & \\
\hline Acciones & Calendario \\
\hline $\begin{array}{l}\text { Mejor cumplimiento de las garantías existentes sobre los productos } \\
\text { tangibles, acompañada de una reflexión sobre las mejoras (futura propuesta } \\
\text { de la Comisión sobre las ventas en línea de bienes, y control de la adecuación } \\
\text { de la legislación sobre consumo) }\end{array}$ & $2015-2017$ \\
\hline $\begin{array}{l}\text { Acción sobre las declaraciones ecológicas falsas, incluida la orientación } \\
\text { actualizada relativa a las prácticas comerciales desleales }\end{array}$ & 2016 \\
\hline $\begin{array}{l}\text { Análisis de la posibilidad de proponer requisitos horizontales relativos a la } \\
\text { disponibilidad de información en materia de reparación en el marco del diseño } \\
\text { ecológico }\end{array}$ & 2018 \\
\hline REFIT de la & 2016 \\
\hline
\end{tabular}

33 Pueden verse, por ejemplo, las MTDs 11, 22, 24 y 43 de la Decisión de Ejecución (UE) 2018/1147 de la Comisión, de 10 de agosto, por la que se establecen las conclusiones sobre las MTD en el tratamiento de residuos. 


\begin{tabular}{|l|l|}
\hline eficacia & \\
\hline $\begin{array}{l}\text { Evaluación de la posibilidad de elaborar un programa independiente de } \\
\text { ensayos sobre la obsolescencia programada }\end{array}$ & 2018 \\
\hline $\begin{array}{l}\text { A reserva de la evaluación de los proyectos piloto actualmente en curso, } \\
\text { estudiar los posibles usos de la huella ambiental de los productos para medir y } \\
\text { comunicar la información medioambiental }\end{array}$ & A partir de 2016 \\
\hline $\begin{array}{l}\text { Acción sobre la contratación pública ecológica: mejor integración de los } \\
\text { requisitos de la economía circular y apoyo a una mayor utilización de ese tipo } \\
\text { de contratación pública, especialmente mediante planes de formación, } \\
\text { reforzando su uso en los procedimientos de contratación pública de la } \\
\text { Comisión y en los fondos de la UE }\end{array}$ & A partir de 2016 \\
\hline
\end{tabular}

FUENTE: Anexo del Plan de acción de la UE para la economía circular" [COM(2015) 614 final; énfasis en el original].

En el siguiente eslabón de la cadena de valor, que es la fase del consumo, el Plan anuncia siete medidas que resultan particularmente vagas salvo en dos frentes bien conocidos que se comentan a continuación:

- Mecanismos voluntarios de mercado: aunque se reconoce la confusión reinante ante la proliferación de distintivos de calidad ambiental, se sigue confiando en que el etiquetado de los productos pueda inducir en los consumidores cambios de comportamiento que, al influir en la demanda, reorienten la oferta hacia los postulados de la economía circular. Pero, en realidad, la acción propuesta consiste en estudiar cómo incrementar la eficacia de la etiqueta ecológica de la UE. La vía para hacerlo, en el marco del vigente Reglamento 66/2010, de 25 de noviembre de 2009, relativo a la etiqueta ecológica de la UE, es la integración de la eficacia material en los "criterios ecológicos específicos" para cada categoría de productos que se aprueban y revisan mediante Decisión de la Comisión. Sin embargo, no parece que esto se esté haciendo de forma sistemática. Por ejemplo, en una de las más recientes, que es la Decisión relativa a los alojamientos turísticos, aunque hay previsiones sobre prevención y gestión de residuos, se sigue limitando su objeto a "promover la utilización de fuentes de energía renovables, ahorrar agua y energía, reducir los residuos y mejorar el medio ambiente local", sin hacer ni 
una sola referencia a la economía circular ${ }^{34}$. Lo mismo sucede en la nueva regulación del distintivo para los productos de la agricultura ecológica ${ }^{35}$.

- Contratación pública: Desde la perspectiva de la demanda de obras, suministros y servicios por parte del Sector Público, en cambio, sí se han registrado avances. Como es sabido, tras una larga evolución que no resulta necesario evocar, "[E]n toda contratación pública se incorporarán de manera transversal y preceptiva criterios sociales y medioambientales siempre que guarden relación con el objeto del contrato, en la convicción de que su inclusión proporciona una mejor relación calidad-precio en la prestación contractual, así como una mayor y mejor eficiencia en la utilización de los fondos públicos" (artículo 1.3 LCSP). De este modo se insta la incorporación en los pliegos siempre que sea posible en atención a la naturaleza del contrato- de cláusulas medioambientales que pueden operar como requisitos de solvencia del contratista, como prescripciones técnicas, como criterios de adjudicación y como condiciones especiales de ejecución. Por lo que se refiere a los criterios de adjudicación, destaca, a los efectos que aquí importan, la previsión según la cual "se valorarán condiciones ambientales mensurables, tales como el menor impacto ambiental, el ahorro y el uso eficiente del agua y la energía y de los materiales, el coste ambiental del ciclo de vida, los procedimientos y métodos de producción ecológicos, la generación y gestión de residuos o el uso de materiales reciclados o reutilizados 0 de materiales ecológicos [artículo 145.3.h) LCSP; énfasis añadido]. De hecho, "previa justificación en el expediente, los contratos se podrán adjudicar con arreglo a criterios basados en un planteamiento que atienda a la mejor relación coste-eficacia, sobre la base del precio o coste, como el cálculo del coste del ciclo de vida" (artículo 145.1 LCSP; énfasis añadido). En relación con esto último se ha dicho que "el CCV es el sistema que adopta la UE para fijar el coste de una obra, servicio o suministro de forma alternativa a su precio" tanto en procedimientos de selección mediante criterio único (subasta) como multicriterio (concurso) y que,

34 Decisión (UE) 2017/175 de la Comisión, de 25 de enero de 2017, relativa al establecimiento de los criterios de la etiqueta ecológica de la UE para el alojamiento turístico.

35 Reglamento (UE) 2018/848 del Parlamento Europeo y del Consejo, de 30 de mayo de 2018, sobre producción ecológica y etiquetado de los productos ecológicos y por el que se deroga el Reglamento (CE) no 834/2007 del Consejo. 
sin venir impuesto por las directivas europeas, en el artículo 148 LCSP "el legislador español ha establecido una preferencia en el uso del CCV por sobre otros sistemas" (LAZO VITORIA, 2018, 129-144). La definición del concepto de ciclo de vida confiere protagonismo a criterios de economía circular ${ }^{36}$ cuya aplicación, sin embargo, por el momento se ve dificultada por el alto grado de complejidad técnica que entraña el cálculo de su coste (SÁNCHEZ MORÓN, 2018, 632).

El Plan de acción es consciente de que con esto no agota los problemas que plantea el "rompecabezas del consumo" pero los rehúye como si de momento no hubiera voluntad política para intervenir decididamente en esta fase que es el auténtico motor de la economía de mercado. La tímida alusión a la "fiscalidad" entre los "instrumentos económicos" que pueden usarse "para garantizar que los precios reflejen mejor los costes ambientales de los productos" va dirigida a los Estados miembros. Se apunta así a eventuales reformas en los Derechos tributarios nacionales aunque, como habían sugerido el CESE y el CDR, había margen para haber ido más allá mediante la revisión de la Directiva relativa al impuesto sobre el valor añadido introduciendo en ella "tipos reducidos o la exención del IVA para los productos reciclados, así como las actividades de reutilización y reparación".

Por otra parte, se anuncia que la Comisión "actuará" para hacer frente a las prácticas de "obsolescencia programada", que en países como Francia ya se tipifican como delito implicando también, por tanto, al Derecho Penal. Pero por ahora las acciones previstas, insuficientes también para el CESE, consisten en

36 Mucho más explícita que la LCSP es, a este respecto, la Orden PCI/86/2019, de 31 de enero, por la que se publica el Acuerdo del Consejo de Ministros de 7 de diciembre de 2018, por el que se aprueba el Plan de Contratación Pública Ecológica de la Administración General del Estado, sus organismos autónomos y las entidades gestoras de la Seguridad Social (20182025). Entre los "objetivos" del Plan se identifica el de "servir como instrumento de impulso de la Estrategia Española de Economía Circular" (apartado tercero del Anexo). Y entre los "criterios generales de actuación" se explica que "la posibilidad de valoración de la vida útil larga de la compra de material inventariable y del resto de productos y servicios, en detrimento de aquellos productos con obsolescencia programada o vida útil corta, puede ser un instrumento adecuado para poder requerir a los fabricantes que declaren o certifiquen garantías de productos con una vida útil suficientemente larga en cada tipología de material o equipos. En los criterios de la Comisión Europea y en la tabla adjunta se detallan las especificaciones en este sentido para los distintos grupos de productos" (apartado quinto.3 del Anexo). En fin, "la incorporación de criterios de circularidad para mejorar la disposición de materias primas, fundamentalmente a través de las materias primas secundarias, debe realizarse en aplicación del principio de jerarquía de residuos que se promueve desde la normativa europea y el propio ordenamiento jurídico español” (apartado quinto.4 del Anexo). 
seguir estudiando el asunto y, como mucho, en ampliar el plazo de garantía de los productos defectuosos vendidos on line. En todo caso, esto último abre perspectivas de transformación también para el Derecho privado que en sucesivas etapas podrían llegar muy lejos si se tiene en cuenta que, para el órgano consultivo que representa a las organizaciones de trabajadores y empresarios y otros grupos de interés de la UE, en la "Era del Antropoceno" la economía circular presupone "una reorganización completa de la economía en la que deben redefinirse los conceptos de responsabilidad y propiedad".

\subsection{Gestión de residuos}

\begin{tabular}{|l|l|}
\hline \multicolumn{2}{|l|}{ Gestión de residuos } \\
\hline Acciones & Calendario \\
\hline Propuesta legislativa revisada sobre los residuos 2015 \\
\hline $\begin{array}{l}\text { Incrementar la cooperación con los Estados miembros para mejorar } \\
\text { la ejecución de la legislación de la UE sobre residuos, y luchar contra el } \\
\text { traslado ilícito de vehículos al final de su vida útil }\end{array}$ & A partir de 2015 \\
\hline $\begin{array}{l}\text { Intensificar la aplicación del Reglamento revisado sobre traslado de } \\
\text { residuos }\end{array}$ & A partir de 2016 \\
\hline $\begin{array}{l}\text { Promoción de la certificación voluntaria, encabezada por el sector de } \\
\text { las instalaciones de tratamiento de flujos clave de residuos / flujos de }\end{array}$ & A partir de 2018 \\
\hline $\begin{array}{l}\text { Iniciativa sobre la transformación de residuos en energía en el } \\
\text { marco de la Unión de la Energía }\end{array}$ & 2016 \\
\hline $\begin{array}{l}\text { Identificación y difusión de buenas prácticas en los sistemas de } \\
\text { recogida de residuos }\end{array}$ & A partir de 2016 \\
\hline
\end{tabular}

FUENTE: Anexo del Plan de acción de la UE para la economía circular" [COM(2015) 614 final; énfasis en el original].

Cuando el producto se convierte en residuo llega la tercera fase de la cadena de valor. Rige en ella, desde hace cuatro décadas, un sector específico del Derecho Ambiental, el Derecho de los Residuos, que a lo largo de todo ese tiempo se ha ido actualizando continuamente tanto en lo que respecta a sus principios inspiradores como a las técnicas jurídicas habilitadas para hacerlos efectivos. A resultas de estos cambios, este sector normativo responde desde 
hace tiempo al enfoque ciclo de vida pues ordena tanto la producción de residuos como su gestión así como la reincorporación de las materias primas secundarias resultantes en los ciclos económicos ${ }^{37}$. Tiene, pues, un indiscutible carácter precursor que, sin embargo, no le pone a salvo de las transformaciones requeridas por la economía circular. Más aún, en un escenario de "residuo cero", podría incluso llegar a cuestionarse la necesidad de su supervivencia (BACKES, 2016). Siendo ésta una propuesta teórica que no carece de base conceptual ${ }^{38}$, lo cierto es que, en términos prácticos, ese debate no se ha abierto por el momento.

Lo que se discute, más bien, es la aportación que desde este sector normativo se viene haciendo a la consecución del fin de la eficiencia material. En este sentido, en la estela de los documentos políticos que le preceden, el Plan de acción da a entender que el principal problema radica en que esta regulación no se aplica como es debido. De hecho, de las seis "acciones" que contempla en este frente, sólo una consiste en dictar nuevas normas. Se trata de la "Propuesta legislativa revisada sobre los residuos", que se presentó en el mismo "paquete" que la Comunicación de 2015 y que ha culminado su tramitación, con numerosas enmiendas, a mediados de $2018^{39}$.

Pero, en líneas generales, y salvo en aspectos de detalle, el análisis de los textos resultantes confirma la valoración que se hizo de las propuestas en el

37 Para una visión del ramificado sistema de fuentes de este complejo y conflictivo sector normativo puede consultarse SANTAMARÍA ARINAS (2018b). Y, para una síntesis del contenido de la regulación en vigor, SANTAMARÍA ARINAS y MUÑOZ BENITO (2018).

38 Hace ya mucho tiempo que se observó que este sector normativo se asienta sobre conceptos como los de "residuo" y "eliminación" que carecen de base científica. Sin poder aquí abordar esta cuestión, bastará recordar que el concepto jurídico de residuo siempre ha resultado controvertido y que las sucesivas definiciones que se han ido ensayando nunca han resultado completamente satisfactorias tal vez por no haber reparado en que en la Naturaleza los residuos no existen; para las ciencias naturales un residuo es un recurso que no ha sido aprovechado. En cuanto a la "eliminación", las leyes de la termodinámica tienen establecido que la materia ni se crea ni se destruye, únicamente se transforma.

39 Directiva 2018/849 del Parlamento Europeo y del Consejo, de 30 de mayo de 2018, por la que se modifican la Directiva 2000/53/CE relativa a los vehículos al final de su vida útil (DVF), la Directiva 2006/66/CE relativa a las pilas y acumuladores y a los residuos de pilas y acumuladores (DPA) y la Directiva 2012/19/UE sobre residuos de aparatos eléctricos y electrónicos (DRAEE). Directiva (UE) 2018/850 del Parlamento Europeo y del Consejo, de 30 de mayo de 2018, por la que se modifica la Directiva 1999/31/CE, relativa al vertido de residuos (DV). Directiva (UE) 2018/851 del Parlamento Europeo y del Consejo, de 30 de mayo de 2018, por la que se modifica la Directiva 2008/98/CE, sobre los residuos (DR). Directiva (UE) 2018/852 del Parlamento Europeo y del Consejo, de 30 de mayo de 2018, por la que se modifica la Directiva 94/62/CE, relativa a los envases y residuos de envases (DE). 
sentido de que "se actualizan, con retraso, compromisos previos en materia de prevención (donde, por cierto, los verdaderos avances habrá que seguir buscándolos fuera de este sector) y se centra principalmente la atención en dos frentes bien conocidos de la gestión. Se trata, por una parte, de la adaptación de medidas de gobernanza que se conforman con señalar objetivos cuantitativos específicos (para residuos municipales y residuos de envases, exclusivamente) y, sean éstos más o menos ambiciosos, con afinar, en el mejor de los casos, indicadores y mecanismos para su control (sin concretar, más allá de los resultados que depare la "alerta temprana", las consecuencias prácticas del eventual incumplimiento de tales objetivos por los Estados). Y se trata, por otra parte, de la aproximación de los regímenes nacionales de responsabilidad ampliada del productor (que ya están desplazando a las Administraciones públicas en la organización de la parte sustancial del negocio en el mercado del sector)" (SANTAMARÍA ARINAS, 2016).

Visto así, las primeras novedades normativas derivadas del Plan de acción de la Unión Europea para la economía circular han afectado, desde luego, al Derecho de los residuos pero distan mucho de haber provocado en él el mínimo de cambios que se requerirían para poder hablar de una verdadera transformación de este sector normativo.

\subsection{Mercado de materias primas secundarias}

\begin{tabular}{|l|l|}
\hline Mercado de materias primas secundarias & Calendario \\
\hline Acciones & A partir de 2016 \\
\hline $\begin{array}{l}\text { Elaboración de normas de calidad para las materias primas secundarias } \\
\text { (en particular, respecto de los plásticos) }\end{array}$ & Principios de 2016 \\
\hline Propuesta de Reglamento revisada sobre fertilizantes & 2017 \\
\hline $\begin{array}{l}\text { Propuesta de legislación al objeto de establecer requisitos mínimos de } \\
\text { reutilización del agua para el riego y la recarga de los acuíferos }\end{array}$ & $\begin{array}{l}\text { Fomento de la reutilización segura y en particular del agua, y } \\
\text { especialmente orientaciones sobre la integración de la reutilización del } \\
\text { agua en la planificación y la gestión del agua, la inclusión de las } \\
\text { mejores prácticas en los BREF pertinentes, y apoyo a la innovación (a } \\
\text { través de la Asociación Europea para la innovación y Horizonte 2020) y }\end{array}$ \\
\hline
\end{tabular}




\begin{tabular}{|l|l|}
\hline las inversiones & \\
\hline $\begin{array}{l}\text { Análisis y opciones de actuación sobre la interfaz entre las sustancias } \\
\text { y productos químicos, los productos y la legislación en materia de } \\
\text { residuos, en particular sobre la manera de reducir la presencia de las } \\
\text { sustancias y productos químicos preocupantes en los productos y de } \\
\text { mejorar su trazabilidad }\end{array}$ & 2017 \\
\hline $\begin{array}{l}\text { Medidas para facilitar el traslado de residuos en toda la UE, incluido el } \\
\text { intercambio electrónico de datos (y, en su caso, otras medidas) }\end{array}$ & A partir de 2016 \\
\hline $\begin{array}{l}\text { Mayor desarrollo del sistema de información sobre materias primas } \\
\text { de la UE }\end{array}$ & A partir de 2016 \\
\hline
\end{tabular}

FUENTE: Anexo del Plan de acción de la UE para la economía circular" [COM(2015) 614 final; énfasis en el original].

El tramo final que cierra el círculo de la cadena de valor ha dado en llamarse por el Plan de acción "mercado de materias primas secundarias". La noción de materias primas secundarias (MPS) designa aquellos residuos que han dejado de serlo tras un proceso completo de valorización ("fin de la condición de residuo"). Al igual, pues, que los "subproductos", no son residuos y, por tanto, su (re)utilización se rige por el Derecho de los productos. Pero es en la regulación de los residuos donde se venían recogiendo los criterios jurisprudenciales que sirven para su identificación. En España, atendiendo con retraso a las reivindicaciones provenientes del sector empresarial, la Comisión de Coordinación en materia de residuos aprobó en 2015 el procedimiento para la declaración de subproductos (modificado en 2017). Y, aunque ni tal procedimiento ni su modificación se han publicado oficialmente, en 2018 aparecieron las primeras órdenes ministeriales para determinar la condición de dos subproductos ${ }^{40}$. En cambio, "no se ha previsto un procedimiento para que los particulares puedan solicitar la aplicación del concepto fin de condición de residuo" pero ya se han aprobado también las primeras órdenes para dos materias primas secundarias ${ }^{41}$ que vienen a sumarse a otras tres ya

40 Orden APM/397/2018, de 9 de abril, por la que se determina cuándo los recortes de espuma de poliuretano utilizados en la fabricación de espuma compuesta, se consideran subproductos con arreglo a la LRSC y Orden APM/189/2018, de 20 de febrero, por la que se determina cuando los residuos de producción procedentes de la industria agroalimentaria destinados a alimentación animal, son subproductos con arreglo a la LRSC.

41 Orden APM/205/2018, de 22 de febrero, por la que se establecen los criterios para determinar cuándo el aceite usado procesado procedente del tratamiento de aceites usados 
contempladas mediante Reglamentos europeos ${ }^{42}$. Con todo, uno de los "elementos" de la reforma de las directivas del sector era precisamente el de lograr una "mayor armonización y simplificación del marco jurídico de los subproductos y del fin de la condición de residuo". Y, a tal efecto, la Directiva 2018/851 ha retocado los perfiles de ambos conceptos:

- En cuanto a los "subproductos", se acoge que la Comisión pueda fijar criterios detallados pero no mediante actos delegados, como pretendía la propuesta, sino mediante actos de ejecución. Cambia por tanto el procedimiento (ahora, artículo 39.2 DR) pero también el margen de su actuación puesto que "tomará como punto de partida los criterios más estrictos y protectores desde el punto de vista ambiental de entre los adoptados por los EEMM de conformidad con el apartado 3 del presente artículo, y dará prioridad a las prácticas reproducibles de simbiosis industrial". Y los EEMM sólo podrán establecer tales criterios "cuando no se hayan definido criterios a escala de la Unión".

- En cuanto a las "materias primas secundarias", el primer requisito ya no es que la sustancia u objeto "pueda usarse" sino que "se debe usar" para finalidades específicas. Por lo demás, la Comisión tampoco podrá adoptar sus "criterios detallados" mediante actos delegados sino mediante actos de ejecución cuyo contenido habrá de respetar, además, las menciones necesarias que ahora se enumeran minuciosamente. $Y$, en cuanto a los EEMM, "cuando no se hayan establecido criterios a escala de UE", podrán dictar los suyos pero ajustándose a esos mismos requisitos aunque, a falta de criterios a escala UE o nacional, podrán adoptar "decisiones caso por caso" que no será obligatorio notificar a la Comisión pero que se "podrán poner a disposición del público". Se añade también que las condiciones deberán cumplirse antes de

para su uso como combustible deja de ser residuo con arreglo a la LRSC y Orden APM/206/2018, de 22 de febrero, por la que se establecen los criterios para determinar cuándo el fuel recuperado procedente del tratamiento de residuos MARPOL tipo c para su uso como combustible en buques deja de ser residuo con arreglo a la LRSC.

42 Reglamento (UE) no 333/2011 del Consejo, de 31 de marzo de 2011, por el que se establecen criterios para determinar cuándo determinados tipos de chatarra dejan de ser residuos con arreglo a la DR. Reglamento (UE) oํ1179/2012 de la Comisión, de 10 de diciembre de 2012, por el que se establecen criterios para determinar cuándo el vidrio recuperado deja de ser residuo con arreglo a la DR. Reglamento (UE) no 715/2013 de la Comisión, de 25 de julio de 2013, por el que se establecen criterios para determinar cuándo la chatarra de cobre deja de ser residuo con arreglo a la DR. 
que la normativa en materia de productos y sustancias químicas se aplique al material que ha dejado de ser residuo y que la garantía del cumplimiento de los requisitos recae en las personas que utilicen o comercialicen por primera vez el material en cuestión ${ }^{43}$.

En el fondo, en estas reformas subyacen disputas de poder entre la Comisión y los Estados miembros que, a su vez, reflejan las dificultades de armonización que se requiere para ir superando barreras que se oponen a la libre circulación de ciertos subproductos y materias primas secundarias $y$, en definitiva, al avance de la transición hacia una economía más circular. Con todo, no parece que, por sí solas, alteren la dinámica -hoy por hoy, irresistible- de las grandes "cadenas globales de valor" transfronterizas (VENCE DEZA, 2018) ni, por tanto, garanticen el deseo que la Comisión formula en el propio Plan de que "los círculos fueran duraderos, cortos, locales y limpios" (énfasis añadido). A este respecto se ha dicho que "en términos de sostenibilidad son preferibles los ciclos cortos porque permiten reducir el consumo de energía, ahorran contaminación por el transporte, favorecen patrones de consumo colaborativo y facilitan el control de los flujos de recursos" (NOGUEIRA LÓPEZ, 2018).

Pero para ello sería necesario que en la (re)utilización de estos materiales que, como se ha visto, no son residuos, pudiera jugar también algún papel el principio de proximidad ${ }^{44}$. Dicho sea sin desconocer que este principio -que, junto con el de autosuficiencia ya rige, bien que de forma limitada, en la gestión de los residuos- permite imponer restricciones a su traslado que suscitan conflictos con la libre circulación de mercancías en el contexto del mercado

43 Por lo demás, para establecer el marco regulador que permita producir fertilizantes a partir de biorresiduos reciclados y otras materias primas secundarias, la Comisión presentó la Propuesta de Reglamento del Parlamento Europeo y del Consejo por el que se establecen disposiciones relativas a la comercialización de los productos fertilizantes con el marcado CE y se modifican los Reglamentos (CE) o 1069/2009 y (CE) no 1107/200943 que, por el momento no ha culminado su tramitación (SANTAMARÍA ARINAS, 2016). Tampoco lo ha hecho la anunciada "Propuesta de legislación al objeto de establecer requisitos mínimos de reutilización del agua para el riego y la recarga de los acuíferos".

44 De alguna manera parece apuntar en esa dirección el artículo 12.c) de la Ley balear 8/2019 cuando, al precisar las competencias de los municipios, les atribuye, bien que "como servicio no obligatorio, el tratamiento, preferentemente por compostaje, y la preparación para la reutilización, de la fracción orgánica de los residuos municipales ajustada a sus características, siempre que el municipio, solo o asociado, disponga de los medios técnicos y humanos que garanticen su mejor tratamiento y se eviten, con el fin de dar respuesta a los principios básicos de la economía circular, los desplazamientos por transporte de materiales y los consumos y las emisiones que se derivan" (énfasis añadido). 
interior europeo (y aun de la unidad de mercado estatal; SANTAMARÍA ARINAS, 2013). Lo cual, unido a otros datos como que la "simbiosis industrial" evoca la idea de una más estrecha cooperación entre empresas, lleva a pensar que las dificultades apuntadas persistirán si las transformaciones pendientes no acaban afectando también al Derecho de defensa de la competencia.

\section{CONCLUSIONES}

En abstracto, la noción de economía circular presupone cambios que han de afectar a los recursos disponibles ("capital natural"), a su administración (pública y privada) e incluso a la rama de las ciencias sociales que se ocupa de todo ello (Economía política). Es improbable que tales cambios se produzcan sólo con el libre juego de la oferta y la demanda por lo que las transformaciones que impulsa han de ir más allá de lo puramente económico. En cuanto instrumento indispensable para ordenar los cambios sociales también requeridos, el Derecho no puede quedar al margen de tales transformaciones.

Sin embargo, examinadas las causas que han motivado la emergencia de un concepto jurídico de economía circular en el contexto europeo, se aprecia que, más allá de corregir los defectos de una "economía lineal" que impiden hacer efectivos los postulados estratégicos del desarrollo sostenible, lo determinante han sido factores coyunturales como la necesidad de reducir la dependencia de las importaciones de materias primas en un mercado global cada vez más inestable. $Y$ examinados los fines, se observa que lo que se persigue es promover cierto grado de eficiencia en el uso de los recursos (eficiencia material) pero sin renunciar en absoluto a la Economía de mercado.

En el plano práctico, todo esto condiciona lógicamente el debate político sobre la fijación de objetivos tácticos y sobre la metodología a seguir para alcanzarlos. Así, en el estado actual de evolución, se confía en que los objetivos asumidos en el Plan de acción de 2015 pueden conseguirse con acciones ejecutivas y con unas pocas reformas normativas de menor alcance. De hecho, con la única excepción del cálculo del coste del ciclo de vida en el ámbito de la contratación pública y al margen de las dificultades que por el 
momento entraña su aplicación, no hay técnicas jurídicas nuevas sino integración de criterios de eficiencia material en algunas de las ya existentes y, en especial, en las propias del ámbito de la autorregulación.

En estas circunstancias, de cara al futuro está por ver que la economía circular acabe consolidándose como un principio general del Derecho que, en conexión con otros ya conocidos sectorialmente como los de autosuficiencia y proximidad, suscite transformaciones más profundas tanto en el resto del Derecho Público (defensa de la competencia) como en determinados aspectos del Derecho privado (consumo).

\section{BIBLIOGRAFÍA}

BACKES, Chris (2017), Law for a Circular Economy, Eleven International Publishing, Utrecht.

BUSTILLO BOLADO, Roberto (2018), "Integración y eficiencia de los recursos naturales en el ecosistema urbano", en M.R. Alonso lbáñez (dir.), Retos del desarrollo urbano sostenible e integrado, Tirant lo Blanch, pp. 107-132.

CERDÁ TENA, Emilio y KHALILOVA, Aygun (2016), "Economía circular", Economía industrial, 401, pp. 11 a 20.

DE LA VARGA PASTOR, Aitana (2018), "Estudio de la ley catalana 16/2017, de 1 de agosto, de cambio climático, y análisis comparativo con otras iniciativas legislativas subestatales", Revista Catalana de Dret Ambiental, Vol. 9, № 2.

DE SADELEER, Nicolás (2016), Droit des déchets de l'UE: de l'élimination à l'économie circulaire, Bruylant, Bruselas.

- (2017), "La economía circular, entre la valorización y la eliminación de residuos", RADA, 38, pp. 229-246.

FORTES MARTÍN, Antonio (2018), "La revisión del tratamiento jurídico de las mejores técnicas disponibles (MTD)", AJA de 4 de junio de 2018.

GARCÍA GARCÍA, Sara (2018), "Economía circular: 30 años del principio de desarrollo sostenible evolucionan en el nuevo gran objetivo medioambiental de la Unión Europea", Revista de Estudios Europeos, 71, p. 309-321. 
GUDÍN RODRÍGUEZ-MAGARIÑOS, Faustino (2018), "La economía circular: reexaminando los residuos, en relación al objetivo más importante de la UE para el año 2050", Medio ambiente y derecho: revista electrónica de derecho ambiental, 33.

Disponible

en Internet: https://huespedes.cica.es/gimadus/33/01 la economia circular.ht ml [Fecha de último acceso 22 de noviembre de 2018].

HANNEQUART, Jean-Pierre (2016), "Evolución de la política europea de economía circular", Ambienta, 117.

KIRHHERR, REIKE, HEKKERT (2017), "Conceptualizing the circular economy: An analysis of 114 definitions", Resources, Conservation and Recycling, Vol. 127.

JIMÉNEZ HERRERO, Luis M. (2012), "La sostenibilidad como oportunidad ante la crisis: economía verde y empleo", Ambienta, 101, pp. $42-53$.

LAZO VITORIA, Ximena (2018), "La perspectiva ambiental de la Ley 9/2017, de contratos del sector público, especial referencia al coste del ciclo de vida", en la obra colectiva dirigida por ella misma, Compra Pública Verde, Atelier, Barcelona, pp. 129-144.

LETÓN GARCÍA, Pedro (2018), "El análisis del ciclo de vida: metodologías y aplicaciones", en X. Lazo Vitoria (dir.), Compra Pública Verde, Atelier, Barcelona, pp. 347-363.

NOGUEIRA LÓPEZ, Alba (2018), "El complejo equilibrio entre los procesos de liberalización y desregulación con las estrategias de economía circular para un desarrollo sostenible", Universidad de Santiago de Compostela (trabajo aun no publicado que se ha podido manejar por cortesía de la autora).

NORONHA XAVIER, Laécio (2017), "Reinterpretação conceitual do desenvolvimento sustentável em face do planejamento urbano e da economia circular", Revista de Direito Econômico e Socioambiental, vol. 8, n. 1, eneroabril 2017, pp. 233-266, [en línea]. Disponible en https://periodicos.pucpr.br/index.php/direitoeconomico/article/view/17691 [Fecha de último acceso 15 de febrero de 2018]. 
PILLING, David (2019), El delirio del crecimiento: la riqueza y el bienestar de las naciones, Taurus, Barcelona.

PUENTES COCIÑA, Beltrán (2018a), “¿España circular 2030? comentario al borrador de la estrategia española de economía circular", Revista Catalana de Dret Ambiental Vol. IX Núm. 2.

- (2018b) "Gestión y prevención de residuos de aparatos eléctricos y electrónicos (RAEE): una propuesta para promover la economía circular", $A J A$, no 84 , de 12 de noviembre de 2018.

RÖMPH, Thomas J. y VAN CALSTER, G. (2018), "REACH in a circular economy: The obstacles for plastics recyclers and regulators", Review of European, Comparative and International Environmental Law (RECIEL), vol. 27, n. 3, pp. 267-277.

RUIZ DE APODACA ESPINOSA, Ángel María (2019), "Hacia la economía circular. Aspectos destacados de la Ley Foral 14/2018, de residuos y su fiscalidad", AJA de 18 de febrero de 2019.

SÁNCHEZ MORÓN, Miguel (2018), Derecho Administrativo. Parte General, 14aㅗ Ed., Tecnos, Madrid.

SANTAMARÍA ARINAS, René Javier (2018a), “¿Residuos o recursos? EI marco jurídico general de la transición hacia la economía circular", en I. Agirreazkuenaga (coord.), Política de residuos. Análisis jurídico desde Euskadi, IVAP, Oñati, pp. 19-62.

- (2018b), "Anexo documental", en I. Agirreazkuenaga (coord.), Política de residuos. Análisis jurídico desde Euskadi, IVAP, Oñati, pp. 421-445.

- (2018c), "El régimen local ante los retos jurídicos de la economía circular", Cuadernos de Derecho Local, 46, pp. 127-157.

- (2016), "Aproximación jurídica a las medidas de la Unión Europea para la economía circular", Ambienta, 117, pp. 36-45.

- (2014), "¿Hacia la economía circular europea sin los municipios? Una crítica sectorial de la LRSAL", RVAP, 99-100, pp. 2671-2701. 
- (2013), "Monopolio, autosuficiencia y proximidad en servicios públicos autonómicos de gestión de residuos", REDA, 159, pp. 245-268.

- (2012), "Novedades, incentivos y problemas jurídicos del sistema europeo de gestión y auditoría medioambiental (EMAS III)", Revista Aranzadi de Derecho Ambiental, 23, pp. 293-342.

- (2011), "La intervención administrativa en el uso industrial de subproductos y materias primas secundarias", Revista Electrónica de Derecho Ambiental, 22.

- SANTAMARÍA ARINAS, René Javier y MUÑOZ BENITO, Lucía (2018), "Residuos y suelos contaminados", en AAVV, Memento Práctico medio ambiente 2019-2020, Francis Lefebvre, Madrid, pp. 723-757.

- VENCE DEZA, Xavier (2018), "Spaces of Circular Economy: from Global Value Chains to closing the loop and close proximity. The EC subsidiarity principle", (trabajo aun no publicado que se ha podido manejar por cortesía del autor).

- ZINK, Trevor y GEYER, Roland (2017), "Circular Economy Rebound", Journal of Industrial Ecology, Volume 21, Number 3, pp. 593-602. 